\title{
ENTRE A SUJEIÇÃO E A SUBJETIVAÇÃO: REFLEÕES SOBRE AS PRÁTICAS CURRICULARES EM "ESCOLAS QUILOMBOLAS"
}

\author{
Evanilson Tavares de França ${ }^{1}$ \\ Jackeline Rodrigues Mendes $^{2}$
}

\section{Para um início de conversa}

Em sua carta aos jovens, Prigogine ${ }^{3}$ utiliza reiteradamente os termos flutuação e bifurcação. $\mathrm{O}$ químico russo acreditava que são as flutuações que promovem (em verdade, definem) os passos seguintes que serão desenhados (em "areia inexplorada"?) por uma comunidade, uma sociedade, pela humanidade, enfim; é esta leitura que fazemos ao pormos os olhos no fragmento "flutuações do nível microscópico decidem que ramo emergirá em cada ponto de bifurcação, e portanto que evento acontecerá" (grifo nosso).

Flutuação tem a ver com instabilidade, com mutabilidade, com ondulação - com onda. Não é a estabilidade que nos caracteriza. Não é a imobilidade que nos define. O repouso não é nosso lar. Somos seres moventes e é exatamente por estes, nestes e através (atravessamos e somos atravessados) destes movimentos (nessa correnteza, nessa flutuação) que os processos de subjetivação encontram significados: (res)significam-se, (res)significam-nos: experimentando modos de nos constituirmos como sujeitos, num cenário onde saberes e poderes se digladiam e confraternizam-se - agora sim, agora não - tentando aqui pautarmo-nos por uma compreensão (nossa) foucaultiana. E compreender não é mais do que traduzir, isto é, fornecer o equivalente de um texto, mas não sua razão" (RANCIÈRE, 2018, p. 27); e acrescentaríamos: nas razões do tradutor.

Conforme Cardoso Júnior (2005, p. 343), é na emergência do curso A hermenêutica do sujeito que Foucault acresce às suas preocupações anteriores (com o saber e o poder) "uma indagação a respeito das práticas pelas quais nos tornamos sujeitos". Candiotto (2008, p. 88) assinala, a seu turno, que para entender os processos pelos quais o sujeito se constitui, Foucault aborda "a articulação entre subjetividade e verdade pelo viés histórico". Veiga-Neto (2016, p. 107) acrescenta que "Foucault dedicou-se ao longo de sua obra a averiguar não apenas como se constitui essa noção de sujeito que é próprio da Modernidade, como, também, de que maneira nós mesmos nos constituímos como sujeitos modernos".

De qualquer modo, ainda que Foucault tenha declarado que o objetivo de seu trabalho fora "criar uma história dos diferentes modos pelos quais, em nossa cultura, os seres humanos tornaram-se sujeitos" (apud DREYFUS, RABINOW, 1995, p. 231), é seguramente em seu último domínio (ser-consigo) que essa preocupação angaria acentuação: para Foucault, o cuidado de si, cujas práticas são indispensáveis à constituição do sujeito, tem como liame articulador a subjetividade e a verdade, o que se realiza por meio da ascese:

A ascese é o que permite, de um lado, adquirir os discursos verdadeiros, dos quais se tem necessidade em todas as circunstâncias, acontecimentos e peripécias da vida, a fim de se estabelecer uma relação adequada, plena e

\footnotetext{
${ }^{1}$ Doutorando em Educação (FE-Unicamp). Mestre em Ensino de Ciências e Matemática (UFS, 2013). Professor do Colégio Estadual John Kennedy - SEE - Aracaju-SE. E-mail: evanilsont@gmail.com.

2 Doutora em Linguística Aplicada (IEL-Unicamp, 2012). Professora do DEPRAC-FE-Unicamp. E-mail: jamendes@unicamp.br.

3 Carta às futuras gerações. Disponível em: <https://teoriadacomplexidade.com.br/wpcontent/uploads/2017/02/CartaParaAsFuturasGeracoes.pdf $>$. Acesso em: 30 de julho de 2018.
} 
acabada consigo mesmo; de outro lado, e ao mesmo tempo, a ascese é o que permite fazer de si mesmo o sujeito destes discursos verdadeiros, é o que permite fazer de si mesmo o sujeito que diz a verdade e que, por esta enunciação da verdade, encontra-se transfigurado, e transfigurado precisamente pelo fato de dizer a verdade. (FOUCAULT, 2006, p. 400)

É, pois, assente na ideia de cuidado de si, nessa prática filosófica que conduz as pessoas a voltarem para si mesmas e para as técnicas que atuarão nos seus processos de subjetivação, que procuraremos velejar por esses mares movimentados entre subjetivação e sujeição também pelas práticas culturais e curriculares. Alcemos as velas...

\section{A prosa continua...}

Propomo-nos neste artigo a refletir sobre a necessidade imperativa de imbricamento entre as práticas culturais quilombolas e os currículos das escolas localizadas naqueles territórios como condição relevante à formação de sujeitos. "O mar não está [assim] para peixes": não se trata de empreitada de fácil percurso, haja vista a complexidade dos conceitos constitutivos daquele objetivo (práticas culturais e curriculares, sujeição e subjetivação) e dos limites que nos cercam (nossos e deste tipo de documento).

Por onde começar?

\section{Cultura e currículo: uma conversa breve}

Conforme Forquin (1993), a relação entre escola e cultura é embrionária, orgânica. No que concerne à educação, trata-se de processo regido inevitavelmente por conhecimentos, valores, crenças, competências, hábitos. Há sempre alguém que se responsabiliza pela educação de outro alguém. Destarte, é na estreiteza dessa relação que aqueles elementos supracitados se fazem presentes, medeiam e justificam o encontro entre quem se propõe a ensinar e quem objetiva aprender. Noutras palavras: aquilo que se convenciona como conteúdo escolar representa, em verdade, uma porção da cultura que se considera como relevante e por isso mesmo digna de transmissão.

Num mar de calmarias, a relação entre cultura e educação certamente se efetuaria estavelmente, sem flutuações; também sem movimento, sem mudança, sem alterações importantes. De um lado, ter-se-ia "a cultura" e dela extrair-se-ia, sem ondulações relevantes (quiçá, sem nenhuma ondulação), a parcela a ser preservada: que certamente asseguraria a permanência de tudo que fosse considerado elevado, belo e essencial para a formação de uma humanidade civilizada. Do outro lado, estariam professores/as obedientes e competentes na arte de internalização e transmissão da "alta cultura"; também se posicionariam, passivos/as e acríticos/as, os/as estudantes, preferencialmente ávidos/as por aqueles conhecimentos.

Estamos aqui pensando na cultura enquanto kultur, ou seja, no modo como um grupo de intelectuais do século XVIII passou a denominar sua contribuição para a humanidade "em termos de maneiras de estar no mundo, de produzir e apreciar obras de arte e literatura, de pensar e organizar sistemas religiosos e filosóficos [...]" (VEIGA-NETO, 2003, p. 06).

Nessas águas, a tarefa da escola seguiria uma correnteza retilínea e suave, visto que o que ensinar (o conteúdo curricular) já estava dado; restaria aos/às aprendentes absorver, recorrendo à memorização e à imitação, tudo aquilo definido (por um grupo específico de humanos) como digno de incorporação. Deslocando o adágio, o mar estaria para peixes para a educação mergulhada naquele oceano. 
Ocorre que as flutuações existem. Apesar, segundo Laraia (1986), de que as discussões no campo da antropologia ainda não terminaram (e talvez nunca terminem), pois, para tanto, requerer-se-ia uma compreensão exata da natureza humana, é possível, ainda segundo esse mesmo autor, afirmar que a cultura condiciona a visão de mundo, que ela tem uma lógica própria e que a dinamicidade lhe é concernente.

Em Lopes e Macedo (2011), após transcurso pelas idas e vindas da construção do conceito de cultura, encontramos a relevância dos Estudos Culturais nessa trajetória, enquanto movimento de ênfase no social e de articulação entre cultura e poder. Seguindo a clareira aberta por Stuart Hall, para quem "[...] todo e qualquer sentido somente pode ser criado dentro de sistemas de linguagem e significação" (apud LOPES; MACEDO, 2011, p. 202), as autoras "definem" cultura como aquilo mesmo que permite a significação. É nessa seara que nos interessa pensar o currículo: como artefato cultural construído num campo de significação e construtor de significados. Portanto, sua vinculação com a cultura, assim como percebia Forquin em referência às conexões entre escola e educação, é também embrionária.

Tomaz Tadeu da Silva (2003), ao desenhar a caminhada histórica das teorias de currículo, tradicional, crítica e pós-crítica, negrita que essa última ilumina as relações saber/poder e as diferenças. Para os teóricos nela inseridos, sustentados no pós-estruturalismo, "a diferença é essencialmente um processo linguístico e discursivo" (SILVA, 2003, p. 87). À vista disso, é possível discutir questões de gênero, de raça/etnia e de sexualidade: as dicotomias homem/mulher, branco/negro, heterossexual/homossexual são construídas discursivamente; sendo assim, é factível no discurso encontrar sua desconstrução. É também no discurso que se deve colher a compreensão de currículo em vez de entendê-lo como objeto já dado, como uma teoria que "supostamente descobre e descreve um objeto que tem existência independente relativamente à teoria" (SILVA, 2003, p. 12).

Macedo (2006b, p. 105), por sua vez, entende currículo "como um híbrido em que as culturas negociam com-a-diferença" - e um híbrido pós-colonial. E, além de atrelar a noção de currículo às perspectivas culturais, o que aliás é substancial nas teorias pós-críticas, também convoca a ideia de hibridismo, presente em Homi Bhabha (1998), para compor sua compreensão. Para esse, as diferenças são negociadas historicamente e buscam conferir "autoridade aos hibridismos culturais que emergem em momentos de transformação histórica" (p. 21, grifos nossos). Parece ser a partir desse hibridismo, dos processos de negociação que sustentam o currículo e as práticas que dele emergem e que o erguem, que Macedo (2006b, p. 105) apresenta "uma definição alternativa de currículo que o perceba como um espaço-tempo de fronteira entre saberes".

De qualquer modo, independentemente da teoria curricular que o apresenta, a imbricação entre currículo e contexto sociocultural é inegável; assim como também o é o vínculo que esse artefato cultural constrói com o contexto (como agente e como paciente) e, por conseguinte, com os modos de produção e de sujeição/subjetivação do sujeito.

\section{Educação escolar quilombola: uma fotografia $3 \times 4$}

Cremos ser imperativo reverberar, neste interim, o grito ensurdecedor gerado pela ausência daquela modalidade de ensino (Educação Escolar Quilombola) na Lei de Diretrizes e Bases da Educação Nacional 9394/96 (LDB 9394/96). Esse dispositivo, que simbolizava uma luta histórica dos movimentos sociais (também os movimentos negros), inseriu no seu corpo algumas modalidades de ensino (a saber: Educação Escolar Indígena, Educação de Jovens e Adultos, Educação Profissional etc.), mas se fez cega quanto ao atendimento às populações negras formadoras das comunidades remanescentes de quilombos. 
$\mathrm{O}$ atendimento àquela modalidade de ensino, do ponto de vista legal (é importante sublinhar isso), somente se efetivará 16 anos após a outorga da LDB 9394/96 por meio da Resolução CNE/CEB Nº 08/2012, de 20 de novembro, que, segundo ementa, "Define Diretrizes Curriculares Nacionais para a Educação Escolar Quilombola na Educação Básica".

Aqui cabe parênteses. Primeiro, é imprescindível negritar que a luta pela modalidade não significa a inexistência de processos educativos concretos e relevantes nas comunidades quilombolas. Por isso, torna-se contundente o registro do "escolar" na nomenclatura da modalidade em espelho: a disputa era/é por atendimento, na educação formal, em escolas erguidas em quilombos (e também naquelas que se encontram em outros espaços, mas que atendem a estudantes originários/as de comunidades quilombolas), pela implantação e implementação de um currículo "elaborado de modo a articular o conhecimento escolar e os conhecimentos construídos pelas comunidades quilombolas" (Art. $8^{\circ}$, VII).

Segundo: em parágrafo anterior, sublinhamos o atendimento da modalidade "do ponto de vista legal", e o fizemos porque investigações acadêmicas revelam que o cotidiano das escolas localizadas em quilombo, com raríssimas exceções, não se apoia nos preceitos legais constitutivos da Resolução supracitada. Em verdade, nas escolas quilombolas, que, na maioria das vezes, assim são classificadas apenas por conta da localização territorial, a interdição dos saberes e dos sujeitos se materializa na negação à copresença dos modos de fazer, entender, interagir e ser dos/as quilombolas nas práticas curriculares daquelas unidades de ensino, ainda que meninas e meninos da comunidade ocupem os bancos escolares. Esse ocultamento do outro, mesmo em presença dele, é de uma violência inominável. Também é inominável a violência encorpada pelo silêncio daqueles/as que têm ciência desse cenário e optam por não o ver - e muito menos denunciá-lo. Por isso mesmo, a separação entre escolas quilombolas e escolas em quilombo encontre justificativa: naquelas, a Educação Escolar Quilombola é o referencial para a elaboração coletiva de sua proposta curricular; nessas, o desconhecimento e/ou a negação do contexto é a tônica que baliza as práticas pedagógicas.

Nesse contexto, cremos ser importante lembrar, em companhia de Macedo (2006a), que tanto o ato pedagógico quanto o currículo podem ser pensados numa perspectiva de colonização, o que conduziria a escola ao entendimento de um espaço/tempo de reprodução. Contudo, se compreendermos a resistência como o outro do poder, é possível construir atos pedagógicos outros e currículos outros.

Uma possibilidade de construção desse currículo (ainda não de uma escola outra) faz-se presente na própria Resolução acima citada. Segundo aquele documento, o currículo das escolas que trabalham com a Educação Escolar Quilombola, conforme Art. 34,

diz respeito aos modos de organização dos tempos e espaços escolares de suas atividades pedagógicas, das interações do ambiente educacional com a sociedade, das relações de poder presentes no fazer educativo e nas formas de conceber e construir conhecimentos escolares, constituindo parte importante dos processos sociopolíticos e culturais de construção de identidades.

E a proposta pedagógica da escola "deverá estar intrinsecamente relacionado com a realidade histórica, regional, política, sociocultural e econômica das comunidades quilombolas" (Art. 32) e ser construída "[...] de forma autônoma e coletiva mediante o envolvimento e participação de toda a comunidade escolar" (Art. 31, IV). Deverá também incorporar "os conhecimentos tradicionais, a oralidade, a ancestralidade, a estética, as formas de trabalho, as tecnologias e a história de cada comunidade quilombola" (Art. 32, § 20, I) e "as formas por meio das quais as comunidades quilombolas vivenciam os seus processos educativos cotidianos 
em articulação com os conhecimentos escolares e demais conhecimentos produzidos pela sociedade mais ampla" (Art. 32, § 2 ${ }^{\circ}$ II).

Há vários outros dispositivos que aqui poderíamos elencar e que demonstram certo avanço em relação à realidade anterior, quando nem mesmo a modalidade existia. Com a outorga da Resolução em espelho, estabelece-se as Diretrizes Curriculares Nacionais e as responsabilidades para o seu cumprimento. Entretanto, como já apontamos em momento anterior, as incursões investigativas demonstram que os distanciamentos entre as práticas curriculares e as práticas culturais da comunidade quilombola (onde a escola está plantada) permanecem: ou por precariedade na infraestrutura das escolas, ou por carências na formação dos/as professores/as, ou por ausência de diálogos com a contextura sociocultural ou pelo velho preconceito que parece se acomodar nos bancos escolares.

Em verdade, cremos que uma possível saída reside na desconstrução do pensamento moderno (SANTOS; MENESES, 2009) que historicamente vem recorrendo a sistemas de distinções para separar o mundo, traçando linhas abissais que dividem a realidade social em dois universos distintos: "deste lado da linha" e "do outro lado da linha": "A divisão é tal que 'o outro lado da linha' desaparece como realidade, torna-se inexistente e é mesmo produzido como inexistente. Inexistência significa não existir sob qualquer modo de ser relevante ou compreensível" (SANTOS, 2007, p. 71).

Para Santos, a ecologia de saberes representaria um caminho possível de combate à divisão moderna abissal responsável pela promoção da invisibilização de conhecimentos que se encaixam nos esboços que definem o que é ciência, o que é filosofia, o que é religião. E por não se encaixarem são concebidos pelo pensamento abissal moderno como crenças, opiniões, magia, idolatria, entendimentos intuitivos ou subjetivos. Convém ressaltar que a invisibilização cognitiva se configura automaticamente em invisibilização dos sujeitos.

\section{Entre a sujeição e a subjetivação: buscando os modos de produção do sujeito}

Numa pequena obra publicada em 2007, com o título "O que é educação", Brandão transcreve uma carta que teria sido enviada por um chefe indígena (dos Índios das Seis Nações) em resposta a convite feito pelos governantes de Virgínia e Maryland (Estados Unidos), com os quais havia assinado um tratado de paz, para que os indígenas enviassem alguns jovens às "escolas dos brancos". Por contribuir com os nossos intuitos neste item, imitaremos Brandão e transcreveremos o documento, apesar de sua dimensão.

[...] Nós estamos convencidos, portanto, que os senhores desejam o bem para nós e agradecemos de todo o coração.

Mas aqueles que são sábios reconhecem que diferentes nações têm concepções diferentes das coisas e, sendo assim, os senhores não ficarão ofendidos ao saber que a vossa ideia de educação não é a mesma que a nossa.

[...] Muitos dos nossos bravos guerreiros foram formados nas escolas do Norte e aprenderam toda a vossa ciência. Mas, quando eles voltavam para nós, eles eram maus corredores, ignorantes da vida da floresta e incapazes de suportarem o frio e a fome. Não sabiam como caçar o veado, matar o inimigo e construir uma cabana, e falavam a nossa língua muito mal. Eles eram, portanto, totalmente inúteis. Não serviam como guerreiros, como caçadores ou como conselheiros.

Ficamos extremamente agradecidos pela vossa oferta e, embora não possamos aceitá-la, para mostrar a nossa gratidão oferecemos aos nobres senhores de 
Virgínia que nos enviem alguns dos seus jovens, que lhes ensinaremos tudo o que sabemos e faremos, deles, homens. (p. 08-09).

Retornaremos à carta acima transcrita logo mais. Por ora, interessa-nos pensar (em linhas breves) as formas de subjetivação que transformam seres humanos em sujeitos. Conforme o professor Veiga-Neto (2016, p. 111), Foucault teria enumerado três possíveis processos para tal: "a objetivação de um sujeito no campo dos saberes"; "a objetivação de um sujeito nas práticas do poder que divide e classifica" e "a subjetivação de um indivíduo que trabalha e pensa sobre si mesmo". O primeiro modo teria sido trabalhado pelo filósofo francês no campo da arqueologia; o segundo, a genealogia fora a técnica escolhida para o intento, e para trabalhar o terceiro modo de subjetivação, Foucault transitou pelo campo da ética. Ainda segundo VeigaNeto, para o filósofo francês, "nos tornamos sujeitos pelos modos de investigação, pelas práticas divisórias e pelos modos de transformação que os outros aplicam e que nós aplicamos sobre nós mesmos" (idem, ibidem).

Como se percebe, a morte do sujeito decretada por Foucault não significa que as pessoas não existem. O que Foucault faz, e aqui trilhamos por estradas desenhadas por Veiga-Neto (2016), é "dar as costas" para as concepções essencialistas de sujeito ("o sujeito desde sempre aí"). Compreender as maneiras como os sujeitos se constituem é tarefa substantiva em suas pesquisas: ele mesmo faz declaração sobre seu interesse pelo sujeito, que vale a pena transcrever: "Meu objetivo, ao contrário, foi criar uma história dos diferentes modos pelos quais, em nossa cultura, os seres humanos tornaram-se sujeitos. Meu trabalho lidou com três modos de objetivação que transformam os seres humanos em sujeitos" (apud DREYFUS, RABINOW, 1995, p. 231). Em razão disso, cremos ser possível afirmar que nos três domínios foucaultianos (arqueologia, genealogia e ética), subjetivação e sujeição são processos imbricados: primeiro porque os sujeitos fazem parte de uma cultura; segundo (em verdade, uma decorrência do primeiro), há atravessamentos entre os sujeitos: não é possível, parece-nos, pensar, mesmo no terceiro domínio (ética), uma subjetivação independente, assintomática aos condicionamentos socioculturais.

Este nosso entendimento parece encontrar guarida em Frédéric Gross (editor da obra $A$ hermenêutica do sujeito) para quem "de resto, o indivíduo-sujeito emerge tão-somente no cruzamento entre uma técnica de dominação e uma técnica de si. Ele é a dobra dos processos de subjetivação sobre os procedimentos de sujeição, segundo duplicações, ao sabor da história, que mais ou menos se recobrem" (apud FOUCAULT, 2006, p. 637).

O cuidado de si, as técnicas de si ocuparam Foucault notadamente no terceiro domínio: há ricas discussões a respeito nos livros A hermenêutica do sujeito, já citado, e A coragem da verdade. No primeiro, Foucault inicia as suas reflexões a partir do diálogo de Sócrates com Alcibíades. Nele, o intuito do filósofo grego é mostrar as fragilidades da educação do discípulo, que ficara sob a responsabilidade de Péricles e que, por sua vez, a confiou a um velho escravo (Zópiro da Trácia). Alcibíades era aquele que desconhecia sua ignorância; mas, pela posição de seus pais na sociedade grega da época, estava destinado a assumir função importante no governo. Sócrates, então, com o intuito de estimulá-lo a preparar-se para as tarefas que o aguardavam, incita-o a cuidar de si mesmo. Portanto, o cuidado de si, no "Alcibíades", está vinculado ao exercício político, ao cuidado do outro por intermédio das atividades próprias de quem governa.

Na sequência, Foucault investiga o exercício do cuidado de si nos períodos helenístico e romano. De acordo com o filósofo (2006, p. 12), "a incitação a ocupar-se consigo mesmo alcançou, durante o longo brilho do pensamento helenístico e romano, uma extensão tão grande que se tornou, creio, um verdadeiro fenômeno cultural de conjunto". As práticas, não obstante, contrariamente ao que se constata no Alcibíades, não estão voltadas para o exercício de uma profissão ou para a ocupação de determinado cargo no governo, mas para que o indivíduo “[...] 
possa suportar, como convém, todos os eventuais acidentes, todos os infortúnios possíveis, todas as desgraças e todos os reveses que possam atingi-lo" (2006, p. 115).

Há diferenças na aplicação das práticas de si entre epicuristas, estoicos e cínicos. Porém, para o alcance de nossos propósitos, importa-nos enfatizar a dimensão cultural que corporifica as atividades do cuidado de si, tanto no "Alcibíades" quanto nos períodos helenístico e romano. Nossa defesa é que, mesmo que no "Alcibíades", a preocupação do cuidado de si volte-se para os "bem-nascidos", haja vista a necessidade de preparação do indivíduo para o exercício do governo, não se desvincula da dimensão cultural, vez que compõe os modos de fazer e de existir, ainda que destinado a determinado grupo social.

Nos períodos helenístico e romano, a dimensão cultural é evidenciada de modo inconteste, assim nos parece, ainda que a segregação se mantenha: "ora o pertencimento a um grupo fechado - este era o caso, em geral, dos movimentos religiosos -, ora a capacidade de praticar o otium, a skholé, o ócio cultivado, o que representava uma segregação de tipo mais econômico e social" (FOUCAULT, 2006, p. 157).

Acreditamos que as rápidas linhas traçadas até aqui viabilizam o nosso retorno aos trechos da carta transcrito acima (BRANDÃO, 2007). Naquele documento, o chefe dos Índios das Seis Nações, ao recusar a proposta dos líderes políticos de Virgínia e Maryland, recorre à seguinte justificativa: “[...] aqueles que são sábios reconhecem que diferentes nações têm concepções diferentes das coisas e, sendo assim, os senhores não ficarão ofendidos ao saber que a vossa ideia de educação não é a mesma que a nossa". E conclui: "[...] para mostrar a nossa gratidão oferecemos aos nobres senhores de Virgínia que nos enviem alguns dos seus jovens, que lhes ensinaremos tudo o que sabemos e faremos, deles, homens" (p. 09).

Depreende-se daí que a educação (melhor seria: os diversos modos de educar), ainda que se processe sustentada no cuidado de si, não se desligará das práticas culturais erguidas e que erguem determinada comunidade e os sujeitos que a ela dão sentido e que dela e nela significam, apreendem as significações e a significar. Esta nossa defesa não tem como fito reduzir a relevância do cuidado de si para o processamento de uma subjetividade (movente) mais ciente de si mesma. A ideia que nos embala é apenas negritar a relevância do contexto sociocultural nos modos pelos quais o sujeito efetiva as práticas de si: as ferramentas, as técnicas e os procedimentos utilizados no cuidado de si encontram-se na contextura sociocultural que o sujeito atravessa e que o atravessam.

Considerando a escola, convém sublinhar que os conteúdos que ela seleciona, explora e valoriza "[...] não são, com efeito, somente saberes no sentido estrito. São também conteúdos mítico-simbólicos, valores estéticos, atitudes morais e sociais, referenciais de civilização" (FORQUIN, 1993, p. 147). Aqui, obviamente, cabem algumas questões: 1) De onde são extraídos esses saberes? Quem os define como válido? Quais atitudes morais e sociais devem ser consideradas "referenciais de civilização"?

Em relação à Educação Escolar Quilombola, Brasil (2012, Art. 34) destaca que "o currículo deve considerar, na sua organização e prática, os contextos socioculturais, regionais e territoriais das comunidades quilombolas [...]". Não obstante, as investigações acadêmicas desdobradas em escolas localizadas em comunidades quilombolas, como já citado, demonstram a ausência de diálogos entre as práticas curriculares daquelas unidades de ensino e as práticas culturais do quilombo: para Dilmar Luiz Lopes (2012, p. 219), "urge a transformação e construção de uma perspectiva política, pedagógica que promova o compromisso com os saberes práticos dos quilombos, amparado nas Diretrizes Curriculares Nacionais para a Educação Escolar Quilombola"; Maroun, que sediou suas investigações na Comunidade Quilombola de Santa Rita do Bracuí, além de concluir que na escola não se aprende a ser quilombola, percebeu a ausência da comunidade no contexto escolar; Gonçalves (2013) move- 
se pelos meandros dos processos de construção identitária e pelos vínculos que tais processos estabelecem (ou não) com as práticas escolares. Para essa pesquisadora, "em relação ao reconhecimento da identidade quilombola, a pesquisa revelou que a escola não contribui ainda para a constituição dessa discussão no currículo" (p. 205).

\section{Finalizando a conversa}

Compreendemos educação (também a formal) como processo movente, inquieto flutuante. Também como instrumento tanto de sujeição como de subjetivação daqueles/as que entram na escola e dão sentido e significado à ação pedagógica/curricular, sejam eles/elas pais/mães, estudantes, professores/as ou mesmo representantes da comunidade local, vez que, ao instalar-se em determinado lugar, ainda que não queira, mesmo sem ciência disso, a escola altera os modos de existir daquela realidade e tem suas maneiras de agir atravessadas pelo contexto sociocultural onde está plantada.

Quando pensamos nas comunidades quilombolas, mesmo que não as compreendamos como grupos isolados e não afetados por outros modos de existir, o entendimento e diálogo íntimo com a contextura sociocultural ganha ainda mais relevância: porque grande parcela desses grupos encontra-se um tanto afastada das comunidades vizinhas e localizada na zona rural - o que assegura a conservação de certas práticas culturais que os marcam historicamente; porque os preceitos legais assim o determinam (e eles são resultantes de lutas históricas); porque (e mais importante) vivemos em um país no qual o racismo é um fato inconteste; por isso, precisamos utilizar de todas as ferramentas possíveis para combatê-lo - e deve-se exigir da escola um lugar na vanguarda desta luta.

Iniciamos estas discussões com o intuito de refletir sobre a necessidade imperativa de imbricamento entre as práticas culturais quilombolas e os currículos das escolas localizadas naqueles territórios como condição relevante à formação de sujeitos. Vimos que as práticas escolares/curriculares, e a carta do chefe dos Índios das Seis Nações comprova isso, funciona como instrumento tanto de sujeição quanto de subjetivação daqueles/as que as vivenciam. Todavia, é possível que, na escola, esse processo (sujeição/subjetivação) transcorra a partir de um trabalho em que o sujeito olhe para si mesmo e o faça não em direção ao individualismo, mas a partir da utilização de técnicas que o levem ao cuidado de si mesmo - o que conduziria ao cuidado do outro. Em se tratando da Educação Escolar Quilombola, defendemos, as ferramentas e os procedimentos para a realização das práticas de si precisam dialogar intimamente com a realidade histórico-cultural do quilombo.

\section{Referências}

BHABHA, H. K. O local da cultura. Belo Horizonte: Editora UFMG, 1998

BRANDÃO, C. R. O que é educação. São Paulo: Brasiliense, 2007.

BRASIL. Resolução $n^{o}$ 08, de 20 de novembro de 2010. Disponível em: < $\underline{\text { http://portal.mec.gov.br/index }}$ php?option=com_docman\&task>. Acesso em: outubro de 2012.

CANDIOTTO, C. Subjetividade e verdade no último Foucault. Trans/Form/Ação. São Paulo, v. 31, n. 1, p. 87-103, 2008. 
CARDOSO JÚNIOR, H. R. Para que serve uma subjetividade? Foucault, tempo e corpo. Psicologia: reflexões e crítica, v. 18, n. 03, p. 343-349, 2005.

DREYFUS, H. L.; RABINOW, P. Michel Foucault, uma trajetória filosófica: para além do estruturalismo e da hermenêutica. Tradução de V. Portocarrero. Rio de Janeiro: Forense Universitária, 1995.

FORQUIN, J. -C. Escola e cultura: as bases sócias e epistemológicas do conhecimento escolar. Porto Alegre: Artes Médicas do Sul, 1993.

FOUCAULT, M. A hermenêutica do sujeito. Tradução de M. A. Fonseca e S. T. Muchail. São Paulo: Martins Fontes, 2006.

GONÇALVES, T. A. V. Tornar-se quilombola: política de reconhecimento e educação na comunidade negra rural de Santana (Quatis, RJ). Rio de Janeiro: PUC/RJ, 2013. Tese de Doutorado, Pontifícia Universidade Católica do Rio de Janeiro, 2013.

LARAIA, R. B. Cultura: um conceito antropológico. Rio de Janeiro: Zahar, 1986.

LOPES, A. C.; MACEDO, E. Teorias de currículo. São Paulo: Cortez, 2011.

MACEDO, E. Currículo como espaço-tempo de fronteira cultural. Revista Brasileira de Educação. v. 11, n. 32, maio/ago. 2006a.

MACEDO, E. Currículo: política, cultura e poder. Currículo sem fronteira, v. 6, n. 2, p. 98113, jul./dez. 2006b.

RANCIÈRE, J. O mestre ignorante: cinco lições sobre a emancipação intelectual. Belo Horizonte: Autêntica, 2018.

SANTOS, B. S. Para além do pensamento abissal: das linhas globais a uma ecologia de saberes. Novos Estudos, v. 79, n. II, nov. 2007.

SANTOS, B. S.; MENESES, M. P. Epistemologias do sul. Coimbra: Edições Almedina, 2009.

SILVA, T. Documentos de identidade: uma introdução às teorias do currículo. Belo Horizonte: Autêntica, 2003.

VEIGA-NETO, A. Cultura, culturas e educação. Revista Brasileira de Educação, Rio de Janeiro, n. 23, maio/jun./jul./ago. 2003.

VEIGA-NETO, A. Foucault e a educação. Belo Horizonte: Autêntica, 2016. 